
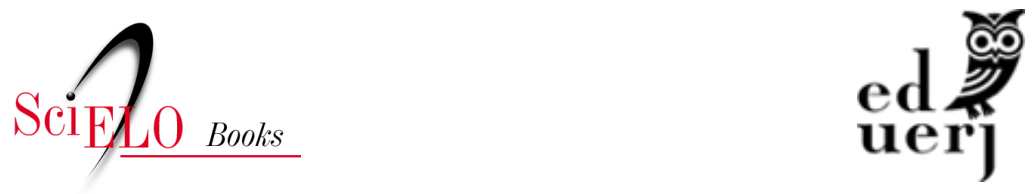

\title{
Prefácio
}

\section{A leitura e o tornar-se texto em contexto de ver o mundo: um livro e seu sentido}

\author{
Luiz Antonio Gomes Senna
}

\section{SciELO Books / SciELO Livros / SciELO Libros}

SENNA, L.A.G. Prefácio - A leitura e o tornar-se texto em contexto de ver o mundo: um livro e seu sentido. In: FERNANDES, A.P., and LOPES, P.C., eds. $O$ cotidiano escolar de crianças, jovens e adultos em rodas de conversas [online]. Rio de Janeiro: EDUERJ, 2020, pp. 21-27. ISBN: 97865-87949-02-4. https://doi.org/10.7476/9786587949024.0002.

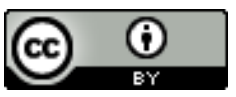

All the contents of this work, except where otherwise noted, is licensed under a Creative Commons Attribution 4.0 International license.

Todo o conteúdo deste trabalho, exceto quando houver ressalva, é publicado sob a licença Creative Commons Atribição 4.0.

Todo el contenido de esta obra, excepto donde se indique lo contrario, está bajo licencia de la licencia Creative Commons Reconocimento 4.0. 


\section{Prefácio \\ A leitura e o tornar-se texto em contexto de ver o mundo: um livro e seu sentido}

Luiz Antonio Gomes Senna

Não basta abrir a janela

Para ver os campos e o rio.

Não é bastante não ser cego

Para ver as árvores e as flores.

É preciso também não ter filosofia nenhuma.

Com filosofia não há árvores: há ideias apenas.

Há só cada um de nós, como uma cave.

Há só uma janela fechada, e todo o mundo lá fora; E um sonho do que se poderia ver se a janela se abrisse, Que nunca é o que se vê quando se abre a janela.

Não costumo lançar mão de epígrafes, pois sempre me recordam aquelas melancólicas mensagens impressas nas lápides funerárias, ali apostas para homenagear alguém que já se foi. Pois, não, ninguém se foi aqui, já esclareço. Trago o poema de Alberto Caeiro, o mais querido dos heterônimos de Fernando Pessoa, pois quero iniciar este prefácio exatamente neste desconcertante lugar situado entre o sonho e o mundo, nem um, nem outro, o entre-si. Se, daqui deste lugar, olho para dentro de mim, lá encontro o sonho de mundo em que creio estar, uma ideia que me habita. Se viro o rosto para o outro lado, lá encontro o mundo, livre de mim, soberano e fiel a si mesmo. E no entre-si estou eu, ciente ou 
não da frágil relação que me liga a ambas as pontas: nesse lugar, me torno leitor. Não é o ato de ler que me torna um leitor, mas sim a consciência de que todo ato de ler é uma produção de sentido que une um sonho a um certo mundo. Não há leitura que negue o mundo, tampouco mundo que se possa pôr em mim no lugar da leitura. E tudo isso é pura filosofia, da boa, com o que cuidemos de sentar freio em Caeiro: não neguemos sonhos e filosofia à leitura; cuidemos, isso sim, de lhes ter nos plurais, de sonhos e filosofias, cada qual um desejo de ver o mundo, um modo de ler.

Embora possamos - e devamos - ter a "leitura" como uma singular faculdade humana, o "ato de ler" que esta nos faculta não cabe no singular. Os atos de ler se realizam de variados modos, não porque estejam regulados por várias categorias de modos de ler, mas sim porque nossos desejos de ver um mundo são muito diversos e, mais uma vez, não por que tenhamos várias categorias de desejos de leitura, mas sim, porque nós somos todos diversos, tendo os mais diversos desejos e sonhos de ver o mundo. Sob uma tal perspectiva, é difícil compreender como a leitura é tratada nas tradiçôes da cultura escolar. Afinal, alguém pode ensinar uma pessoa a ler? Com base em que critérios se pode definir se alguém lê bem ou mal?

Quando, na cultura escolar, se estabelece como meta de formação o ensino da leitura, normalmente, se está fazendo referência ao domínio do código escrito. Nesse imaginário escolar, a expressão "fulano sabe ler" significa "é alfabetizado", ao passo que "fulano não sabe ler" significa tanto "é analfabeto" como "é mal alfabetizado". Não importa se fulano domina outras tantas dezenas de formas de leitura; se não domina o código escrito, será considerado analfabeto e, consequentemente, não leitor. A tradição escolar é intransigente quando o que está em jogo é a escrita alfabética como ferramenta de produção e leitura de textos.

Contudo, não lhe basta o domínio do código escrito e a capacidade de desenvolver atos de leitura em interação com textos 
escritos. A escola tem certos parâmetros que regulam a forma como devemos desenvolver o ato de leitura. É preciso ler sozinho, ler em silêncio, ler em repouso, ler o que é certo e edificante; é preciso ser, portanto, um ser que a escola deseje ter como aluno. Portanto, ali não se ensina a ler; ensina-se a usar a escrita alfabética e a se transformar em um ser que pratica o ato de ler de certo modo.

Ademais, o termo ler náo seria exatamente o mais adequado para definir o que se espera do leitor em um contexto de tradição escolar. No "Dicionário de filologia e gramática”, um reconhecido marco da introdução da Linguística no Brasil, a leitura ainda é definida como

A interpretação da e s c r i t a consiste, essencialmente, na transposição dos elementos da g r a fi a em elementos da fo n a çã o mesmo quando não se articulam estes últimos elementos no aparelho fonador mas há apenas uma evocação mental desses elementos (leitura silenciosa) (Câmara Jr., 1956, p. 219, grifo do autor).

Da definição, compreende-se a "interpretação da escrita" de forma bem mais estreita do que, aqui, considera-se como "ato de ler". Para além das características de que já tratamos no parágrafo anterior, há outras duas propriedades a destacar na definição de Câmara Jr.

A primeira delas, bem literal, relaciona a leitura da escrita à descoberta de uma língua falada que lhe dá sentido. Trata-se, segundo ele, da transposição do material gráfico em fonação, oralizada ou interna. Ainda que não se tenha nisso, em princípio, a ideia de que deva haver perfeita isomorfia entre as formas gráfica e fonológica no ato de leitura, a definição de Mattoso Câmara permite suscitar que a transposiçáo de uma forma à outra dá-se de forma natural e perfeitamente previsível a partir de alguma forte relação entre elas. Sabe-se, todavia, que, além da imensa variedade dialetal que compóe o Português do Brasil, as representaçôes fonológicas 
estão sujeitas a variaçóes, tanto idioletais como decorrentes de um sem número de fatos fonêmicos inexistentes na forma gráfica. Para a maioria dos falantes do Português do Brasil, a leitura de um texto escrito não se resume a sua mera transposição, pois envolve um número significativo de elaboraçóes mentais que, de fato, transformam a escrita em uma representação fonológica. Esse processo de elaboraçóes tende a ser ainda mais complexo, à medida que os fatores idioletais, dialetais e fonêmicos tornem menos transparente a relação entre elas.

A segunda propriedade a se destacar da definição de Mattoso Câmara está subentendida no termo "transposição". Nesse processo sistemático de conversão de uma forma em outra, observa-se que não é autorizado ao leitor elaborar o sentido do texto, assumir, portanto, aquele lugar do "entre-si". Nesse exercício solitário de decodificação, cumpre-lhe extrair o sentido que emana soberanamente do texto. É o texto quem diz, fazendo-se, assim, texto, antes mesmo de ser leitura de alguém. É sobretudo nessa propriedade que se assenta, de forma mais clara, a concepção de leitura que perpassa as práticas da tradição escolar: um aluno (no singular) decifrando um texto (soberano).

Desde o final do século passado e avançando neste século, os estudos sobre o processo de leitura trouxeram muitas contribuiçôes para a compreensão do "ato de ler", de suas propriedades, do ponto de vista intelectual e dos fatores interferentes. Desses estudos, além da caracterização da leitura como um processo mental de produçáo de sentidos naquele lugar entre o sonho e o mundo, restou claro que o texto escrito não se institui por si mesmo, isolado do leitor ou do mundo. Como ressalta Dumont (2001, p. 44),

Trata-se sim de examinar como um texto se expóe, explicitamente ou não, à leitura, ou às leituras que são feitas ou podem ser feitas, como se permite a liberdade de leitura, ou se faz sua restrição, a partir da vivência do leitor. A compreensão de um texto, a ser efetivada pela 
leitura crítica, enreda-se na percepção das relaçôes entre o texto e o contexto.

O sentido de um texto transita, na realidade, entre o contexto de mundo do qual deriva e somente no qual pode ser buscado, e o contexto de significaçóes daquele que o lê. A matéria gráfica, no caso do texto escrito, nada mais contém do que um corpus de palavras que suscita a ligação entre esses dois contextos. Esse é o motivo pelo qual somos hoje levados a definir o texto desde o ponto de vista de quem o lê, a quem se expóe e se faz pleno de sentido. Náo um sentido que lhe é inerente, mas, sim, um sentido que deriva da experiência de leitura. Todo texto é texto para alguém. Não o sendo, não é nada, pura matéria gráfica rabiscada.

A expressão "ensino de leitura" vem sendo paulatinamente substituída por "tornar-se leitor", em um movimento que busca deslocar o imaginário de uma prática decifradora e apócrifa, por um processo global de desenvolvimento de um sujeito leitor de mundo. Nesse movimento, perde espaço o método, o texto estereotipado, e entra em cena um professor mediador de sonhos, mundos, contextos e os "entre-si" que habitam em seus alunos. Nas palavras de Paulo Freire (1996, pp. 33-5),

Antes de qualquer tentativa de discussão de técnicas, de materiais, de métodos para uma aula dinâmica assim, é preciso, indispensável mesmo, que o professor se ache 'repousado' no saber de que a pedra fundamental é a curiosidade do ser humano. E ela que me faz perguntar, conhecer, atuar, mais perguntar, reconhecer. $(\$)$ [...] O exercício da curiosidade a faz mais criticamente curiosa, mais metodicamente 'perseguidora' do seu objeto. Quanto mais a curiosidade espontânea se intensifica, mas, sobretudo, se 'rigoriza', tanto mais epistemológica ela vai se tornando. (\$) [...] O exercício da curiosidade convoca a imaginação, a intuição, as emoções, a capacidade de conjecturar, de comparar, na busca da perfilização do objeto ou do achado de sua 
razão de ser. (\$) [...] Não haveria existência humana sem a abertura de nosso ser ao mundo, sem a transitividade de nossa consciência. (\$) Quanto mais faço estas operações com maior rigor metódico tanto mais me aproximo da maior exatidão dos achados de minha curiosidade.

A curiosidade faz-nos abrir as janelas e olhar o mundo como nos sugere Alberto Caeiro. Nesse excerto de Freire (1996), encontramos a melhor definição para a prática mediadora do formador de leitores: aquilo que "convoca a imaginação, a intuição, as emoçôes, a capacidade de conjecturar, de comparar, na busca da perfilização do objeto ou do achado de sua razão de ser".

Trago Paulo Freire e Fernando Pessoa, este, vestido de Alberto Caeiro, ao prefaciar este livro, porque vejo em ambos a síntese da motivação de todos os seus capítulos. Partindo de um movimento de ação que tem a escola real e seu professor como protagonistas, o projeto "Roda de Conversas - cotidiano e escola", o livro já se institui como uma proposta de desafio às tradiçóes da escola, entre as quais, acrescento, aqui, a da formação do leitor. Não bastasse isso, o livro propóe, de forma ainda mais desafiadora, concentrar-se no sujeito-leitor da Educação de Jovens e Adultos, presente, tanto no consagrado discurso de Paulo Freire, como nas inquietaçóes existenciais carregadas de pragmatismo histórico de Alberto Caeiro.

Distribuídos em duas partes, os capítulos subsequentes nos proporcionam um panorama desse leitor de mundo que desafia a escola e seus professores a se revolucionarem a cada dia de aula. Pessoas cuja riqueza de conhecimentos de vida e de mundo contrasta com a pobreza dos valores escolares e sua dificuldade de se tornar mediadora de seu desenvolvimento enquanto leitores, pois é muito bom reconhecê-los aqui, retratados como sujeitos escolares; não alunos do "fracasso escolar", e sim alunos plenos, no direito e no processo de aprendizagem. Identificá-los assim é um passo 
necessário para reconhecê-los agentes de seu próprio desenvolvimento como leitores.

Esta é uma obra coerente com sua origem: suscitadora de rodas de conversa sobre a escola e seus atores.

\section{Referências}

CÂMARA Jr., J. M. Dicionário de filologia e gramática. Rio de Janeiro: Lozon, 1956.

DUMONT, L. "Contexto, leitura e subjetividade”. In Transinformação, v. 13, n. 1, pp. 43-47, 2001.

FREIRE, P. Pedagogia da autonomia. São Paulo: Paz e Terra, 1996.

PESSOA, F. Obra completa. Rio de Janeiro: Aguilar, 1960. 